\title{
Anthropogenic dynamics and recovery of disturbed landscapes at the Far East Russia permafrost area
}

\author{
Pavel E. Tikhmenev ${ }^{1,2 *}$, Andrey A. Smirnov ${ }^{2,3}$, Evgeniy A. Tikhmenev ${ }^{1,2}$, and \\ Galina V. Stanchenko ${ }^{1,2}$ \\ ${ }^{1}$ Institute on Biological Problems of the North, Russian Academy of Science, Far Eastern \\ Branch, Magadan, Russia \\ ${ }^{2}$ Nort-East State University, Magadan, Russia, \\ ${ }^{3}$ Federal Research Institute of Fishery and Oceanography, Moscow, Russia
}

\begin{abstract}
The results of studies of anthropogenic landscapes functioning with an assessment on the processes of natural self revegetation are summarized. The principles of accelerated restoration of the ecological and aesthetic value of disturbed landscapes at the permafrost zone are substantiated, based on the data obtained during studying the selfrevegetation processes on disturbed complexes. Development of placer and ore deposits of mineral resources is leading to deep transformation of landscape and to destruction of soil-vegetable complexes. The processes caused by mining-technical activity are leading to variable mechanisms of degradation of soil and vegetables often having complex impact. Results of study of sustainability of soil-vegetable complexes to the impact of mancaused activity have showed the dependence from the structure of the soil profile and it characteristic, from the character of genetic horizons, frozen status of the landscape elements, form the structure and biomass and productivity of vegetation cover.
\end{abstract}

\section{Introduction}

During exploitation of deposits at the permafrost zone of Far North-East, major technogenic processes of denudation, transportation and accumulation of material occur, in a volume comparable with the naturally occurring active morpholithogenesis [1].

At the beginning of our research, there was no data on the self-revegetation potential of the landscapes disturbed during exploitation of ore deposits at the North-East, as well as the was no experience their biological reclamation. The aim of research is to create an ecological basis of restoration of disturbed sites of permafrost landscapes.

* Corresponding author: tpavel@mail.ru 


\section{Materials and methods}

The studies were carry out in light coniferous taiga communities. Main forest - forming species of region under investigation is larch (Larix cajanderi), which grows on various elements of the mountainous relief. Widely distributed cider-plank communities (Pinus pumila), occupying the mountain slopes, so were studied. Succession processes in selfrenewing vegetation of the landscape after mining operation were observed. In during field research were carried out of plant cover and soil of natural and disturbed sites after mining operation. Widely approved methods were used [2,3]. Species given name we follow by Flora and vegetation of Magadan region [5].

\section{Results and discussion}

Our observations were made on the technogenic formations at the Kubaka gold ore deposit, situated in Omolon river basin, the largest tributary of the Kolyma river. It was founded that natural revegetation process of disturbed natural complexes at larch woodlands and cedarplank communities is usually unsufficient The Kubaka mine is located at the altitudes of 650$750 \mathrm{~m}$ above sea level on Kolyma upland. That predefines the difficulties in the processes of natural revegetation of disturbed complexes. Our studies showed that there is practically no self-revegetation in large-fragment rock dumps and quarries. The process of plant communities natural revegetation in the areas of surface disturbances, such as geological exploration tranches and temporary roads proceeds more successful (Fig.1).

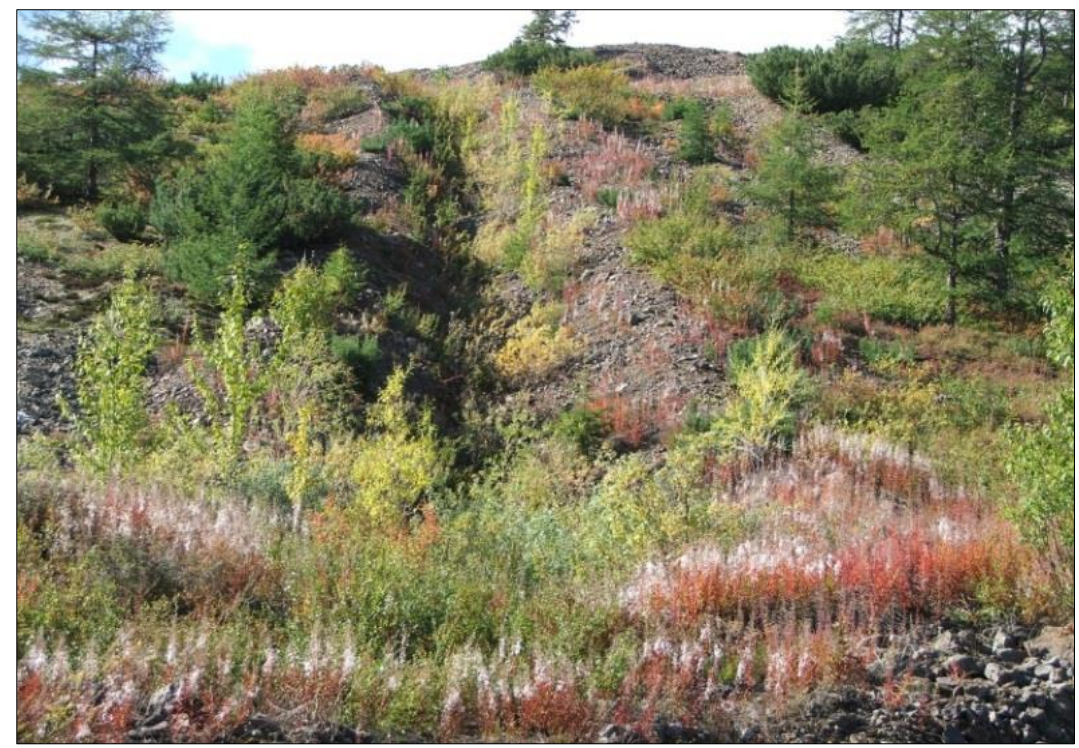

Fig. 1. Self-revegetation on the geological trench, disturbed during geological exploration (Kubaka gold ore deposit, 560-570 m above sea level).

Most common species of plants sattled on technogenic formations are perennial grasses, shrub species of willows (Salix krylovii, S. alaxensis, S. schwerenii, S. glauca), dog rose (Rosa acicularis), Kuril tea (Potentilla fruticosa), meadowsweet (Spiraea beauverdiana), lean birch and Middendorff's birch shrubs (Betula exilis, B. middendorffii). Chosenia (Chosenia arbutifolia) and poplar (Populus suaveolens) are also common on the disturbed lands. Larches prefer denudated areas of the landscape with a sufficient amount of fine 
particles. In natural conditions, self-restoration of vegetation cover is aimed to form the initial type of forest that grew here before the exploitation. This process proceeds most successfully if the time of violation of the integrity of natural complexes coincides with the larch seeding productive years, observed at intervals of once every 5-7 years in the specific conditions of permafrost landscapes. If disturbances of natural complexes occurred in not productive years, then wasteland with low biodiversity are formed, where self-healing of forest communities can last for decades. Since humification is mainly a biochemical process, this similarity of deposits of different ages confirms low rates of humus formation and inhibition of microbiological activity. If the natural zones of vegetation are preserved in close proximity, the natural distribution of seeds into technogenic zones is ensured, which accelerates the formation of sods and the stabilization of the surface of disturbed objects. The depth of violations, the graveliness of the substrate, the shape and height of the man-made dumps determine the rates of succession processes, which proceed differently in the regenerated groups of plants on objects of different genesis.

Post-technogenic landscapes at the first stages of restoration are characterized by the absence any vegetation, low microbiological activity and a slow circulation of substances (Fig. 2). The small amount of «living matter» involved in the biosynthesis and accumulation of nutrients predetermines very low rates of natural restoration of disturbed landscapes in the initial period. The data obtained during our studies allows us to determine the direction of succession processes and the duration of regeneration pause of plant groups. Selfrevegetation of the disturbed vegetation cover begins 5-6 years after the removal of the technogenic press. At the same time, humus accumulation, its composition stabilization in the emerging soil and vegetation complexes of technogenic landscape elements after ten years or more, approaches its zonal type. A wide range of conditions for the settlement of pioneer plants, intrinsic of technogenic landscapes, is reflected in the structure and productivity of the vegetation.

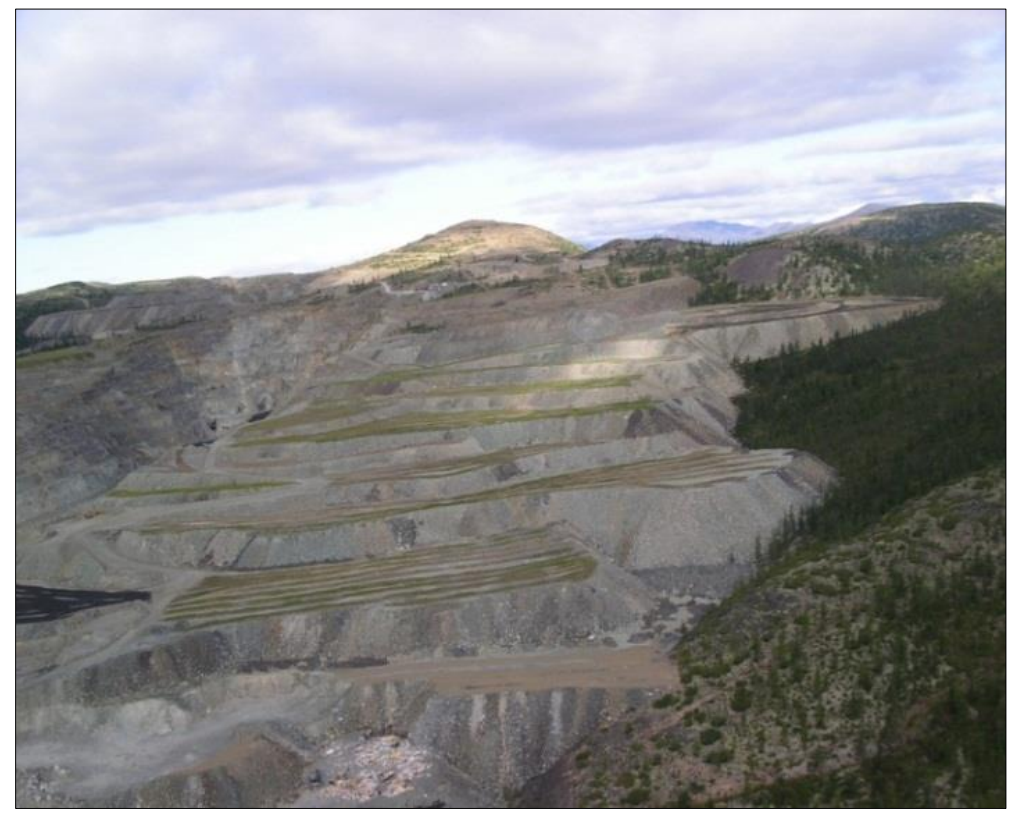

Fig. 2. Reclaimed waste rock dumps at the Kubaka mine (light coniferous taiga).

The features of the natural revegetating soil-plant complexes of disturbed sites consist in a wide variation in the projective plant cover - from the complete absence of vegetation to 
clearly expressed regenerative phytocenoses. At the initial stages of natural revegetation process, its influence on the formation of the soil profile is offset by the heterogeneity of the mineral base and the variety of ecological niches of disturbed areas. Plants usually settle in places where the necessary conditions for their growth are created, mainly in micro depressions of the relief, where the accumulation of organic material occurs under the condition of sufficient moisture (Fig. 3).

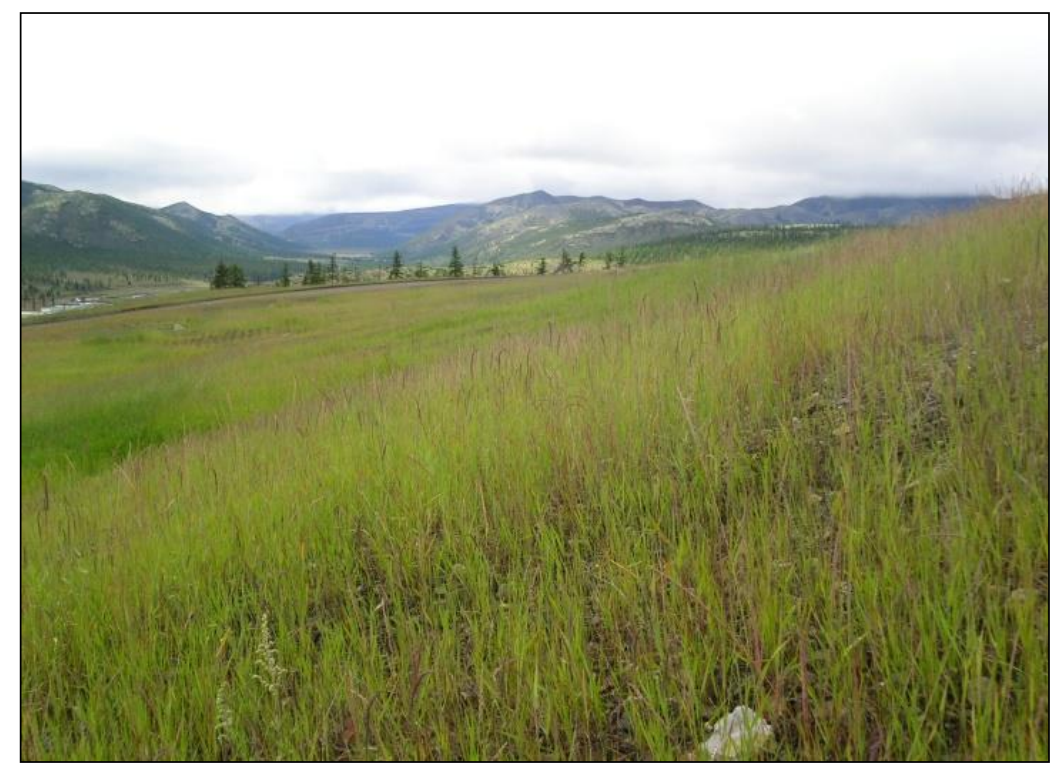

Fig. 3. Reclamation of disturbed sites of the Kubaka gold ore deposit (Omolon basin river) using seeds species of native flora of region, as well adopted to hard surrounding condition of permafrost region.

Post-technogenic landscapes at the first stages of restoration are characterized by the absence of any vegetation, low microbiological activity and a slow circulation of substances. The small amount of «living matter» involved in the biosynthesis and accumulation of nutrients predetermines very low rates of restoration of disturbed landscapes in the initial period.

In self-revegetatied plant complexes there are 1-2 clearly defined dominant species, which are cereals, sedges, fireweeds, stubbleweed, aserisk, saxifrages, wormwoods, astragalus, and ostracisans, which usually do not take place prominent positions in natural plant communities. The source of seed application to disturbed lands is natural plant complexes adjacent to disturbed areas. Often there are cases of settlement of disturbed areas in the cedar-plank belt with typical types of river floodplains, such as poplar (Populus suaveolens) and chosenia (Chosenia arbutifolia). Favorable conditions for the settlement of these species in unusual habitats are provided by active intra-ground condensation of vaporous moisture [4].

Succession processes are significantly accelerated with the accumulation of fine earth material and humus in technogenic forms of relief. The depth of disturbances, the amount of coarse rock material in the substrate, the shape and height of technogenic forms determine the self-revegetation processes that occur differently in the restored plant groups. Areas of surface disturbances, overburden dumps and technological dams are actively overgrown, where usually there is sufficient fine earth, usually adjacent to natural plant communities. Considering the content of organic matter and humic acids under different types of plants, a definite connection can be noted. With an increase in the total supply of organic matter, the 
content of humic acids in it also increases, but it remains two times lower compared with zonal soils.

At the considerably deeply disturbed areas (Fig.2), self-revegetation proceeds extremely slowly, especially in the mountain-tundra (alpine belt). The complete absence of vegetation is characteristic of the main technogenic formations that are formed during the development of ore deposits - quarries, dumps of large waste rocks, which occupy the most areas in the mining area. They are characterized by great dryness, active aeration, lack of fine earth, slightly acidic or alkaline reaction of the substrate. The geochemical composition of waste rocks is characterized by the presence of such compounds as lead, chromium, vanadium, nickel, manganese, tin, copper, zinc, often in concentrations below the maximum permissible values. On such elements of disturbed mountainous landscape, anti-erosion land reclaimaition is required. Sites with deep lithogenic disturbances require the directed formation of the soil-vegetation complexes with the implementation of a full cycle of land reclamation work. The best results in biological stage of land reclamation of disturbed lands are achieved using seeds of local flora species that are most adapted to the harsh conditions of the permafrost zone (Fig.3).

\section{Conclusions}

The study of the structural and functional organization of the natural landscape environment into which the developed mineral deposits are «embedded» provides a basis for optimizing technological processes to accelerate the self-revegetating of disturbed lands. The performed studies provide a theoretical basis for the implementation of remediation work to stabilize the natural environment and accelerate the restoration of the productivity of disturbed lands. The data obtained provide an opportunity to summarize the available experience in order to accelerate the elimination of undesirable consequences of ore deposits in the zone of widespread permafrost and in other parts of the planet.

\section{References}

1. A.A. Pugachev, E.A. Tikhmenev. Structural and functional organization and dynamics of the soil-vegetation complexes of the Far North-East of Russia (NWSU Publishing House,Magadan, 2011) (in Russian)

2. The program and methodology for the study of technogenic ecosystems, (Nauka, Novosibirsk, (1978) (in Russian)

3. Anthropogenic dynamics of the vegetation cover of the Arctic and Subarctic: principles and methods of study. Proceedings of the Botanical Institute RAS, 15 (1995) (in Russian)

4. A.I. Zinchenko, I.M. Papernov., VNII-1, 37, 29-36 (1977) (in Russian)

5. Flora and vegetation of Magadan region (Checklist of vascular plants and outline of vegetation) (IBPN FEB RAS, Magadan, 2010) (in Russian). 